\title{
Multiscale Microstructural Analysis of Austempered Ductile Iron Castings
}

\author{
Kemal Davut ${ }^{1,2}$, Alp Yalcin ${ }^{2}$ and Baris Cetin ${ }^{3}$ \\ 1. Atilim University, Metal Forming Center of Excellence (MFCE), Ankara, Turkey \\ 2. Atilim University, Dept. of Metallurgical and Materials Engineering Department, Ankara, Turkey \\ 3. FNSS Defense Systems Co. Inc., Department of Engineering and Research, Ankara, Turkey
}

Austempered ductile iron (ADI) is a special class of ductile cast iron that offer a good combination of high tensile and fatigue strength, high toughness and wear resistance. In addition, ADI has good damping characteristics, low cost and low density, the latter of which provides light weighting. Those promising properties of ADI ensures reliable service under heavy conditions of shock, impact and wear; and therefore ADI has been used in many applications including gears, drive wheels, rollers, sliders, suspension parts in automotive, defense, heavy-duty vehicle industries [1].

The outstanding properties of ADI is a result of a special microstructure, which is produced by a specific austempering process. This heat treatment process is composed of 2 steps involving austenitization in the range of $850-950^{\circ} \mathrm{C}$ followed by isothermal holding in the range of $250^{\circ} \mathrm{C}-450^{\circ} \mathrm{C}$, which normally should be above the $\mathrm{M}_{\mathrm{s}}$ and below to $\mathrm{B}_{\mathrm{s}}$ temperatures [2]. After this treatment the resulting microstructure is composed of spheroidal graphite particles on an ausferrite matrix, which is a mixture of acicular bainitic-ferrite and carbon enriched austenite. In some cases martensite can also be present.

The present study compares 6 different ADI samples that exhibit up to $1057 \mathrm{MPa}$ ultimate tensile strength and up to $4.97 \%$ elongation. A multiscale microstructure analysis is required to fully understand the microstructure of ADI and then correlate microstructural parameters to mechanical properties. The size, shape, fraction and also the nodularity of graphite particles as well as the matrix microstructure influences the mechanical properties [3]. A simple optical microscope image of as-polished ADI (Figure 1a) is usually enough to characterize the graphite particles, since their average size is in the range of 20 $-50 \mu \mathrm{m}$. However, the details of ausferrite matrix cannot be resolved with optical microscope (figure $1 \mathrm{~b}$ and 1c). The details of the bainitic ferrite of ausferritic matrix can be resolved with field-emission scanning electron microscope (FEG-SEM) as shown in Figure 1d. In order to resolve the carbon enriched austenite regions, electron back-scatter diffraction technique (EBSD) should be employed.

The comparison of microstructure and mechanical properties of the ADI samples has shown that the variation in nodularity values up to $20 \%$ does not correlate with the differences in mechanical properties. On the other hand, the matrix microstructure plays a more important role for determining mechanical properties. The fineness of bainitic ferrite as well as the austenite has significant influence on UTS and elongation values. EBSD measurements shown in Figure 2 reveal two types of austenite: i) film type between bainite platelets and ii) blocky type, between bainite-sheafs and also around prior austenite grains that are not transformed completely. The results reveal that best combination of mechanical properties can be achieved in a microstructure composed of fully ausferrite with finer bainitic ferrite surrounded by $35 \%$ austenite of mainly film type. The present study shows that, even in conventional materials such as ADI, a multi-scale approach is required to fully understand and correlate the mechanical properties resulting from aforementioned specific microstructure. 
References:

[1] K.L. Hayrynen et al, Transaction American Foundrymens Society 2 (2002) p. 929-938.

[2] B. Kovacs, American Foundry Society Transactions 99 (1991), p. 281-286.

[3] A. Trudel and M. Gagné, Can. Metall. Quarterly 36 (1997), p. 289-298.

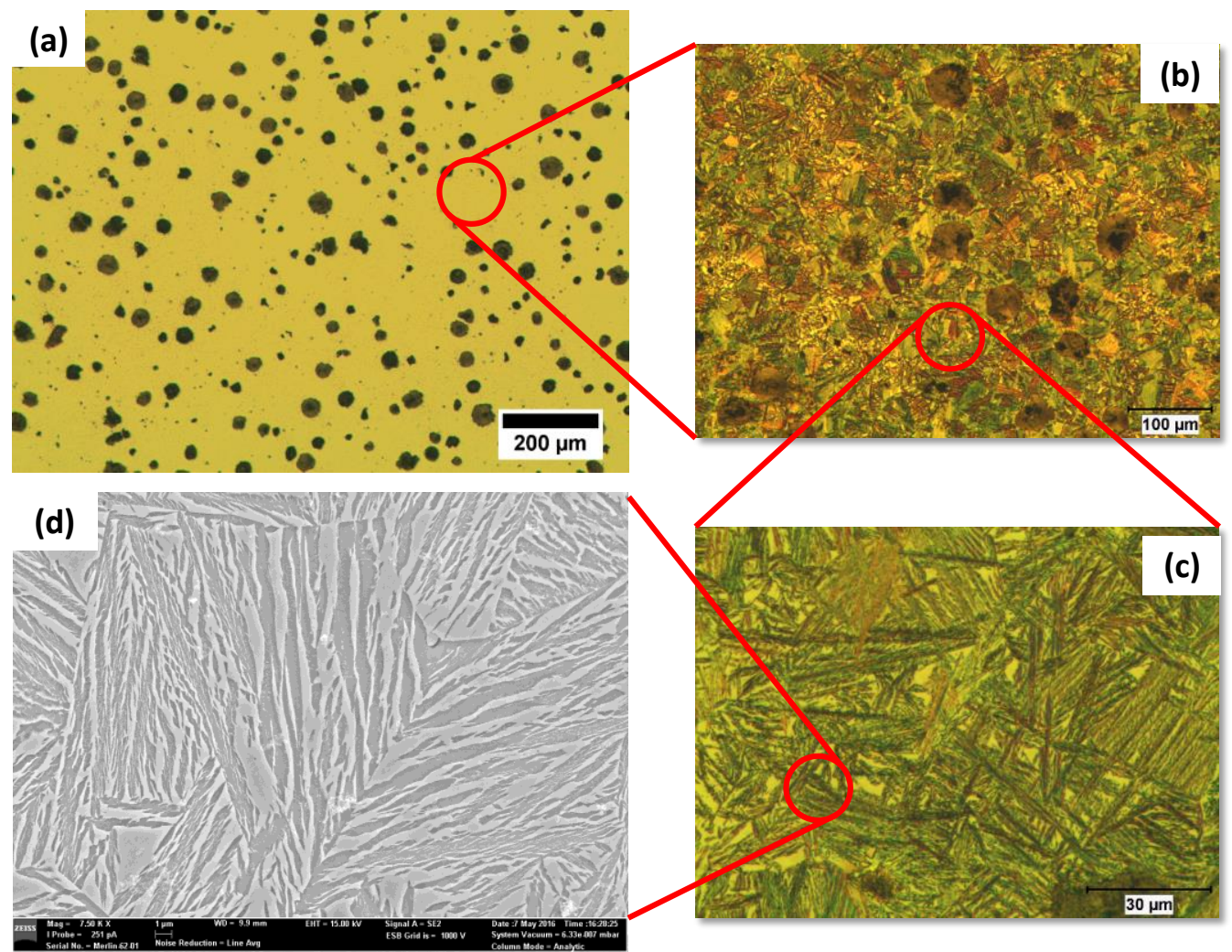

Figure 1. a) As polished microstructure of ADI taken with OM at 50x. Etched OM images of ADI at b) 100x and c) 1000x. FEG-SEM image of ADI at 7500x.
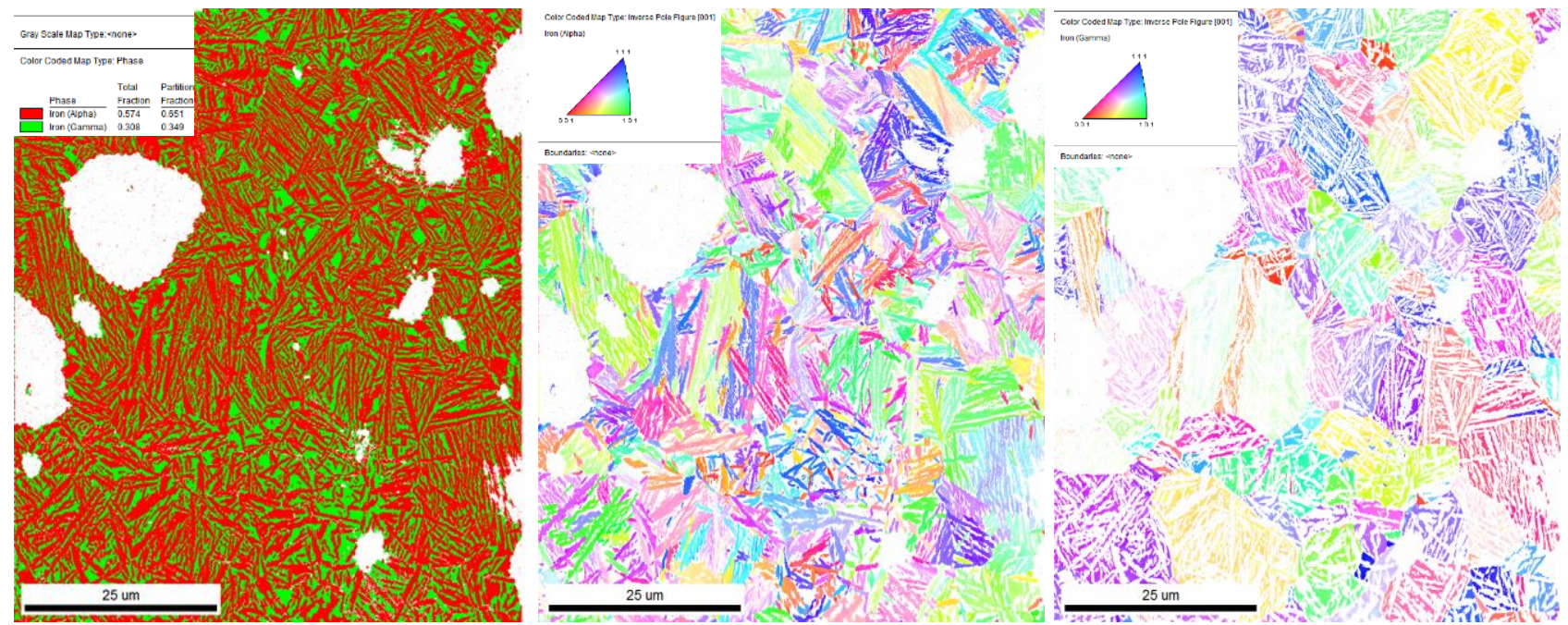

Figure 2. EBSD phase map (left) and "normal direction (ND)" inverse pole figures (IFP) of ferrite (middle) and austenite (right). 